\title{
Light entrainment of retinal biorhythms: cryptochrome 2 as candidate photoreceptor in mammals
}

\author{
Jacques Vanderstraeten ${ }^{1,2} \mathbb{D} \cdot$ Philippe Gailly $^{3}$ D $\cdot$ E. Pascal Malkemper ${ }^{4}$
}

Received: 21 August 2019 / Revised: 8 January 2020 / Accepted: 14 January 2020

(c) Springer Nature Switzerland AG 2020

\begin{abstract}
The mechanisms that synchronize the biorhythms of the mammalian retina with the light/dark cycle are independent of those synchronizing the rhythms in the central pacemaker, the suprachiasmatic nucleus. The identity of the photoreceptor(s) responsible for the light entrainment of the retina of mammals is still a matter of debate, and recent studies have reported contradictory results in this respect. Here, we suggest that cryptochromes (CRY), in particular CRY 2, are involved in that light entrainment. CRY are highly conserved proteins that are a key component of the cellular circadian clock machinery. In plants and insects, they are responsible for the light entrainment of these biorhythms, mediated by the light response of their flavin cofactor (FAD). In mammals, however, no light-dependent role is currently assumed for CRY in light-exposed tissues, including the retina. It has been reported that FAD influences the function of mammalian CRY 2 and that human CRY 2 responds to light in Drosophila, suggesting that mammalian CRY 2 keeps the ability to respond to light. Here, we hypothesize that CRY 2 plays a role in the light entrainment of retinal biorhythms, at least in diurnal mammals. Indeed, published data shows that the light intensity dependence and the wavelength sensitivity commonly reported for that light entrainment fits the light sensitivity and absorption spectrum of light-responsive CRY. We propose experiments to test our hypothesis and to further explore the still-pending question of the function of CRY 2 in the mammalian retina.
\end{abstract}

Keywords Circadian rhythms $\cdot$ Flavin cofactor $\cdot$ Retina $\cdot$ Magnetoreception $\cdot$ Radical pair mechanism

\section{Introduction}

Most biological processes exhibit circadian rhythmicity. Throughout the organism, these biorhythms are regulated by an auto-regulatory transcriptional-translational feedback loop that runs at the level of each cell and is coordinated by the central clock of the suprachiasmatic nucleus (SCN) [1].

Jacques Vanderstraeten

vdstraeten.j@skynet.be

1 Faculty of Medicine, School of Public Health, Environmental and Work Health Research Center, Université Libre de Bruxelles, CP593, Route de Lennik, 808, 1070 Brussels, Belgium

2 Avenue Constant Montald, 11, 1200 Brussels, Belgium

3 Faculty of Medicine, Institute of Neuroscience (IONS), Cellular and Molecular Pole (CEMO), Catholic University of Louvain, Avenue Mounier 53/B1.53.17, 1200 Brussels, Belgium

4 Center of Advanced European Studies and Research (CAESAR), Ludwig-Erhard-Allee 2, Bonn 53175, Germany
Endogenous biorhythms are influenced by diverse environmental factors. Light is a major factor for the synchronization and resetting of endogenous rhythms with the light/dark cycle (light entrainment). In mammals, the retina constitutes the only input pathway of light both to the central pacemaker in the SCN as well as to peripheral pacemakers of the biological clock [2]. Indeed, recent studies have shown that peripheral clocks can be light entrained by inputs directly issued from the retina, independently of the $\operatorname{SCN}[2,3]$. Recent studies have also focused on the skin, the other organ exposed to light, but observations are contradictory. While one study reported that light entrainment of skin biorhythms depends on the retina via a neural pathway and is independent of the SCN [4], another has reported that entrainment directly depends on the UV-sensitive neuropsin (OPN5) photopigments that skin cells contain [5].

The retina was the first organ in which local, autonomous, biorhythms were observed [6]. Retinal biorhythms regulate many eye functions, including visual and non-visual (i.e. circadian) light reception [7]. Many retinal physiologic functions oscillate with a 24 -h period, e.g. transcription and 
translation of photoreceptor genes, neurotransmitter synthesis and release, inter-photoreceptor coupling, disk shedding in rods, and the amplitude of the electroretinogram (reviewed in Buhr et al. [8], and Felder-Schmittbuhl et al. [9]). The light entrainment of retinal biorhythms is directly achieved by photoreceptors of the retina, independently of the SCN $[9,10]$. Similar SCN-independent rhythmicity exists in the cornea and the retinal pigmented epithelium [11]. While the receptor responsible for the light entrainment of the SCN is melanopsin (OPN4), a pigment localized in intrinsically photosensitive retinal ganglion cells (ipRGCs), the precise identity of the receptor(s) responsible for the light entrainment of the retinal biorhythms remains debated $[8,9,11$, 12]. Here, following the underexplored previous suggestion from Buhr et al. [8], we propose that cryptochrome (CRY), and in particular CRY 2, acts as a light-receptor mediating retinal light entrainment in mammals.

\section{State of the art}

\section{Light entrainment of retinal biorhythms}

Different studies have addressed the question of the identity of the photoreceptor responsible for the light entrainment of retinal biorhythms by monitoring the expression of the clock gene Per2 in mouse retinal explants [8, 11-13]. By exposing the explants to phase-shifting pulses of white light at an intensity of $>10^{14}$ photons $/ \mathrm{cm}^{2} / \mathrm{s}$, Ruan et al. [13] reported that, like the SCN biorhythms, the retinal biorhythms show, respectively, a phase delay, or a phase advance, when exposed in the first hours, or the last hours, of the subjective night. Moreover, they reported the dopaminergic circuitry to be crucially involved in the light resetting of retinal biorhythms, suggesting the involvement of amacrine cells and the upstream ipRGCs from which they receive inputs (Fig. 1) [8].

Using transgenic mice, Buhr et al. [8] showed that neither rods or cones nor OPN4 containing ganglion cells were required for the light entrainment of retinal biorhythms under antiphasic $12 \mathrm{~h} / 12 \mathrm{~h}$ light/dark cycles. During the whole light phase, light was provided by LED (between 417 and $530 \mathrm{~nm}$ ) at a constant intensity of $5 \mathrm{~W} / \mathrm{m}^{2}$, which corresponds to about $1.4 \times 10^{15}$ photons $/ \mathrm{cm}^{2} / \mathrm{s}$ at $470 \mathrm{~nm}$. In a follow-up paper [11], using antiphasic $9 \mathrm{~h} / 15 \mathrm{~h}$ light/dark cycles with a light intensity of about $10^{14}$ photons $/ \mathrm{cm}^{2} / \mathrm{s}$ (about $10^{13}$ photons $/ \mathrm{cm}^{2} / \mathrm{s}$ at $370 \mathrm{~nm}$ ), the authors showed, respectively, that $370 \mathrm{~nm} \mathrm{UV}$ light and $417 \mathrm{~nm}$ and $475 \mathrm{~nm}$ blue light can photoentrain retinal biorhythms but $530 \mathrm{~nm}$ green light cannot. Furthermore, they reported that, for a light pulse of $3 \mathrm{~h}$ duration, the minimal intensity needed to cause a phase shift was between $10^{13}$ and $10^{14}$ photons $/ \mathrm{cm}^{2} / \mathrm{s}$ at $417 \mathrm{~nm}$. Using knockout mice, they demonstrated that neither short-wavelength-sensitive cone opsins (OPN1SW), nor the orphan opsin encephalopsin (OPN3) were required, and they identified neuropsin (OPN5) as the responsible photoreceptor [11]. Contrasting these findings, Calligaro et al. [12] found that rods play a crucial role in the lightinduced phase-shift of retinal biorhythms when exposed to light pulses reduced to only $15 \mathrm{~min}$ of duration (intensity of between $10^{13}$ and $10^{14}$ photons $/ \mathrm{cm}^{2} / \mathrm{s}$ ) at wavelengths up to $520 \mathrm{~nm}$. Using a candidate gene approach similar to Buhr et al. [11] they then demonstrated the absence of a lightinduced phase shift in rodless mice. They did, however, find a residual phase shift in rodless retinas when using UV light (395 nm), which they attribute to OPN5 and/or OPN1SW [12].

To sum up the findings to date, the photoreceptor responsible for the light entrainment of retinal biorhythms is thought to be one or several opsins (Table 1) [9]. On the one hand, the precise identity of the receptor(s) remains a matter of debate, and the conflicting evidence is not easy to reconcile [12]. The OPN5 proposed by Buhr et al. [11] has a sensitivity that mainly covers the UV spectrum (maximal absorption at $380 \mathrm{~nm}$, Fig. 2), both in rodents and in humans [18]. Buhr et al. [11] and Calligaro et al. [12], however, observed a phase shift at $470 \mathrm{~nm}$ blue light, which is outside the absorption spectrum of that opsin (Fig. 2), even in mice
Fig. 1 Cellular organization of the mammalian retina. The distribution of photoreceptor cells is species-dependent

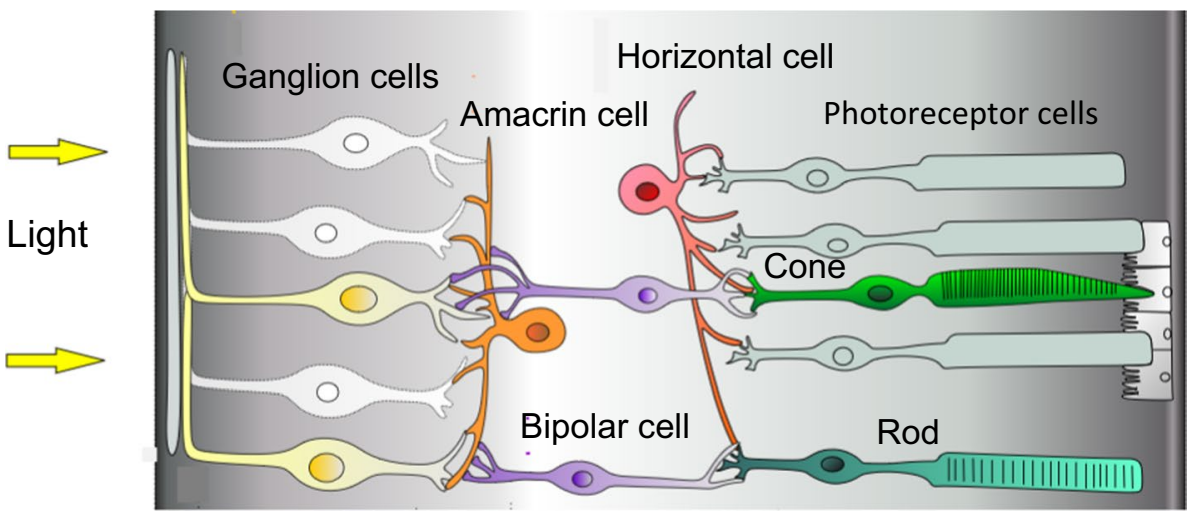


Table 1 Mammalian opsin photoreceptors and their expression pattern, functional role and approximative maximal wavelength sensitivity

\begin{tabular}{|c|c|c|c|c|c|c|}
\hline \multirow[t]{2}{*}{ Abbreviation } & \multirow[t]{2}{*}{ Name } & \multicolumn{2}{|l|}{ Location } & \multirow[t]{2}{*}{ Main role } & \multicolumn{2}{|c|}{$\begin{array}{l}\text { Maximal sensitiv- } \\
\text { ity }\end{array}$} \\
\hline & & Eye & Other & & Mouse & Human \\
\hline \multicolumn{7}{|l|}{ OPN1 } \\
\hline OPN1LW & L-cone opsin & Cones & & Visual $^{\mathrm{a}}$ & & $560 \mathrm{~nm}$ \\
\hline OPN1MW & M-cone opsin & Cones & & Visual $^{\mathrm{a}}$ & $510 \mathrm{~nm}$ & $530 \mathrm{~nm}$ \\
\hline OPN1SW & S-cone opsin & Cones & Skin ${ }^{\mathrm{b}}$ & Visual $^{\mathrm{a}}$ & $360 \mathrm{~nm}$ & $420 \mathrm{~nm}$ \\
\hline OPN2 & Rhodopsin & Rods & Skin $^{\mathrm{b}}$ & Visual $^{\mathrm{a}}$ & $500 \mathrm{~nm}$ & \\
\hline OPN3 & Encephalopsin & $\begin{array}{l}\text { Rods, cones } \\
\text { Plexiform layers } \\
\text { Ganglion cells }\end{array}$ & $\begin{array}{l}\text { Skin }^{\mathrm{b}} \\
\text { Brain }^{\mathrm{c}}\end{array}$ & Non-visual & & \\
\hline OPN4 & Melanopsin & ipRGCs & & Non-visual $^{\mathrm{d}}$ & $480 \mathrm{~nm}$ & \\
\hline OPN5 & Neuropsin & RGCs & Skin ${ }^{b}$ & Non-visual & $380 \mathrm{~nm}$ & \\
\hline \multicolumn{7}{|c|}{ Go/RGR opsins } \\
\hline RRH & Peropsin & RPE & & Non-visual & & \\
\hline RGR & $\begin{array}{l}\text { Retinal G protein- } \\
\text { coupled receptor }\end{array}$ & RPE & & Non-visual & & \\
\hline
\end{tabular}

All three different types of OPN1 exist only in trichromats, such as humans (mouse, e.g., have only M- and S-cone opsins)

$L W$ long wavelength, $M W$ middle wavelength, $S W$ short wavelength, $R P E$ retinal pigmented epithelium

${ }^{a}$ Rods and cones also have non-visual functions (pupillary light response, ipRGCs-mediated light response)

${ }^{b}$ Melanocytes and keratinocytes

${ }^{\mathrm{c}}$ Cortex, cerebellum, diencephalon

${ }^{\mathrm{d}}$ The main function of OPN4 is circadian photoreception, but it also takes part in the pupillary light response and incidentally in visual photoreception [11,14-18]
Fig. 2 Absorption spectrum of the main opsins of the human retina and cryptochrome (CRY) in its oxidized, ground state (in mouse, OPN1SW has a maximal sensitivity at about $360 \mathrm{~nm})$. The bar at the bottom of the graph displays the range of wavelength sensitivity of retinal biorhythms (densely hatched: reported in experiments using light-entrainment; less densely hatched: reported in experiments using lightinduced phase shifting). LW: OPN1LW; MW: OPN1MW; SW: OPN1SW [8, 11, 12, 14, 18, 19]

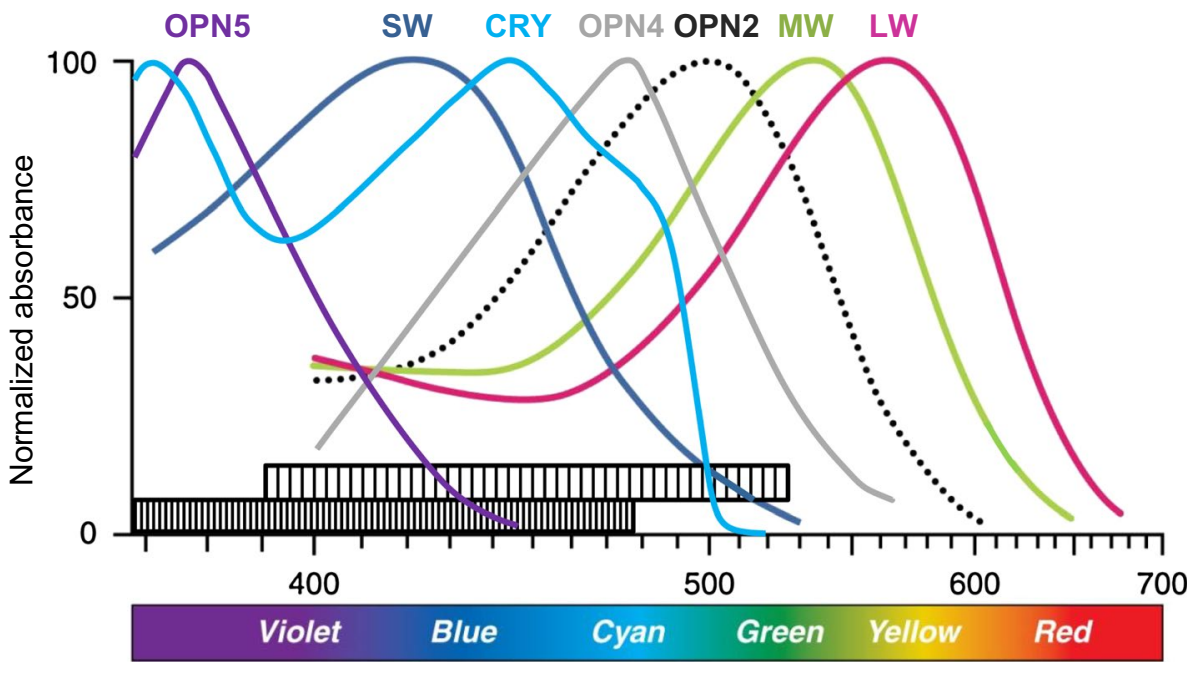

Wavelength (nm)
[18]. As noted by the authors themselves and by FelderSchmittbuhl et al. [9], the role of OPN5 in the entrainment of retinal rhythms in diurnal mammals thus remains uncertain. Furthermore, the lens is much less UV-transparent in diurnal than in nocturnal mammals [20], and the expression of OPN5 in the retina of humans and non-human primates remains controversial $[12,18,21]$. On the other hand, the reported involvement of rods in retinal light entrainment by Calligaro et al. [12], as well as these authors' proposal of a contribution of OPN1SW containing cones, raises the question (stated by the authors themselves) of why the light response of retinal biorhythms requires light intensities that are several orders of magnitude above the sensitivity threshold of rod opsins (rhodopsin, or OPN2, $10^{7}$ photons $/ \mathrm{cm}^{2} / \mathrm{s}$ ) and cone opsins $\left(\sim 10^{8}\right.$ photons $\left./ \mathrm{cm}^{2} / \mathrm{s}\right)$, respectively [22]. Finally and most puzzlingly, Calligaro et al. [12] reported a 
phase shift of retinal biorhythms at $520 \mathrm{~nm}$, while Buhr et al. [11] could not light entrain these biorhythms with $530 \mathrm{~nm}$ green light. Even though the experimental paradigms of the studies mentioned were different (light entrainment vs pulse-induced phase shifting), the discrepancies between their respective results raise questions.

\section{Cryptochrome photopigments}

CRY are flavoproteins that are highly conserved from bacteria to humans (Fig. 3). They are between 500 and 700 amino acids in size depending on the phylum or class considered. The N-terminal domain is highly conserved from their photolyase ancestor (the photolyase homology domain, or PHR), while the 40-250 amino acid long C-terminal $\alpha$-helical domain is less conserved. The $\mathrm{C}$-terminal domain seems essential for CRY activity, whether or not it depends on light [23]. Animal CRY are classified into two main functional groups, type I and type II CRY. Type I CRY, also known as Drosophila-type CRY, are photoreceptive, while type II, or vertebrate-type, CRY are generally thought to only fulfill non-light-dependent functions [24]. In all organisms, CRY are key components of the cellular clock, where they are part of the negative limb of the autoregulatory transcription-repression feedback loop. In mammals, they bind to the protein PER (period) to repress CLOCK/BMAL1-dependent transcription [25].

In plants and insects, CRY act as (non-opsin) photopigments that entrain the biological clock directly through the light response (photoreduction) of their flavine adenine dinucleotide (FAD) cofactor (cf. Fig. 2). The absorption spectrum of FAD in its ground, fully oxidized state is quite broad, with two maxima, one in the visible range around $450 \mathrm{~nm}$ and another in the UV range around $370 \mathrm{~nm}$
(Fig. 2). At $400 \mathrm{~nm}$, the absorption is around $60 \%$ of the maximal absorption (Fig. 2) [19]. Only $\mathrm{FADH}^{\circ}$, the neutral radical form of the flavin cofactor in the active form of plant CRY and of the particular animal type IV Cry (CRY 4, see below) that mammals do not express, absorbs light up to $650 \mathrm{~nm}[19,26]$. The light sensitivity threshold of CRY has been mostly studied in plant CRY 2 where it is expressed as the photosynthetic photon flux density in micromol $/ \mathrm{m}^{2} / \mathrm{s}\left(1 \mu \mathrm{mol} / \mathrm{m}^{2} / \mathrm{s}=6 \times 10^{13}\right.$ photons $\left./ \mathrm{cm}^{2} / \mathrm{s}\right)$. When measured based on the phosphorylation response of CRY 2, this threshold lies around $0.1 \mu \mathrm{mol} / \mathrm{m}^{2} / \mathrm{s}$ for $30 \mathrm{~min}$ of $450 \mathrm{~nm}$ light illumination [27]. By studying its light-induced degradation, Weidler et al. [28] showed that plant CRY 2 responds to $0.01 \mu \mathrm{mol} / \mathrm{m}^{2} / \mathrm{s}$ under $2 \mathrm{~h}$ of blue light illumination, with saturation at about $5 \mu \mathrm{mol} / \mathrm{m}^{2} / \mathrm{s}$. They also showed that CRY-dependent signaling response in plants can integrate light energy over time, with $2 \mathrm{~h}$ blue light causing about $65 \%$ and $80 \%$ of CRY degradation at 0.01 and $0.1 \mu \mathrm{mol} / \mathrm{m}^{2} / \mathrm{s}$, respectively. To our knowledge, $0.01 \mu \mathrm{mol} / \mathrm{m}^{2} / \mathrm{s}$ is the lowest fluence studied to date in plant CRY. As the light response of CRY relies on the interaction between the FAD cofactor and its binding site in the highly conserved PHR domain, that threshold can be expected to not show large variations with CRY type [24]. In this respect, Zoltowski et al. [26] showed that point mutations in the FAD binding site cause variation of no more than a factor 2 in the light sensitivity of the reaction constant of FAD photoreduction, unless they concern the tryptophan (Trp) residues of the Trp triad that is involved in the light-response of CRY. This difference in light sensitivity is of the same order as the variation observed between the highly sensitive type IV CRY and plant CRY [26].

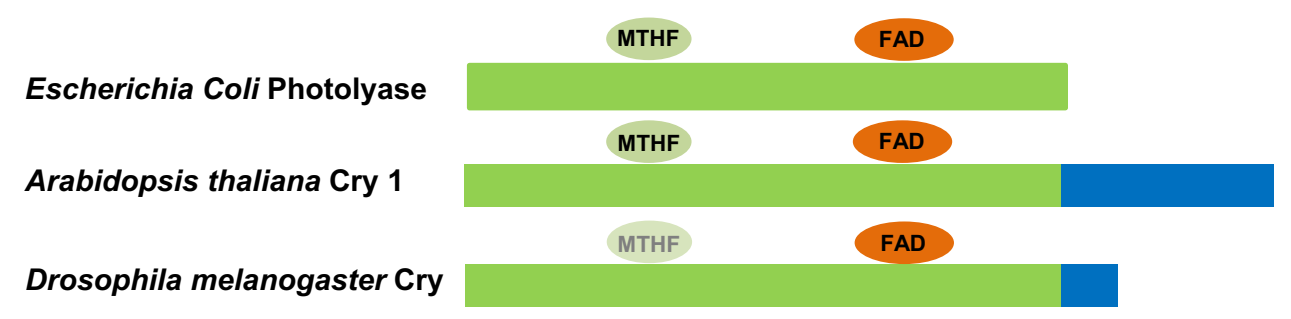

Mus musculus Cry 1

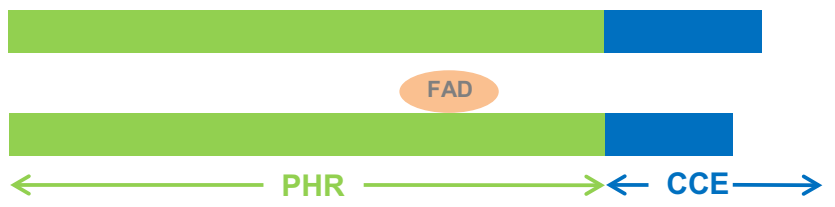

Mus musculus Cry 2

Fig. 3 Schematic representation of the structures of photolyase of bacteria (Escherichia coli) and representative cryptochromes (CRY) of plant (Arabidopsis thaliana), insects (type I CRY of Drosophila melanogaster), and mammals (type II CRY of mice, Mus musculus), with approximate binding sites of 5-methyltetrahydrofolate (MTHF) (equivocal in Drosophila) and flavin adenine dinucleotide (FAD) cofactors (equivocal in mammalian CRY 2). PHR photolyase homology region domain, $C C E \mathrm{C}$-terminal extension domain [23-25] 


\section{Cryptochromes of mammals}

In mammals, two type II CRY exist, CRY 1 and CRY 2. CRY 1 is the prominent subtype in most cells and tissues, where it plays an important and well-documented role in the cellular clock feedback loop (review in [29]). We know much less about the function of mammalian CRY 2. In the retina, its function is considered marginal compared to CRY 1 , and only a partial role could be identified in photopic electroretinogram rhythms [30]. Furthermore, the expression pattern of CRY 2 in the mammalian retina has been a matter of debate. While Thompson et al. [31] initially found CRY 2 to be preferentially localized in retinal ganglion cells, subsequent studies reported CRY 2 to also be located in amacrine, horizontal and bipolar cells, as well as in cones (see Fig. 1) [9]. A recent study challenged these conclusions, demonstrating the lack of specificity in two commercial CRY 2 antibodies using tissue from CRY 2 knockout mice as negative controls [30].

Based on the known light dependence of the circadian function of CRY in plants and the high structural homology between type II CRY of vertebrates and plant CRY, including the Trp triad [32], it has been proposed that CRY of the retina are responsible for circadian photoreception in vertebrates [33]. To investigate the role of CRY in nonvisual photoreception in mice, Van Gelder et al. [34] studied the pupillary constriction reflex in response to blue light $(470 \mathrm{~nm})$. Mice with severe degeneration of the photoreceptors $(r d /$ $r d$ mice) retained substantial photic sensitivity for pupillary responses and the light-induced phase shift of circadian rhythms. The authors showed that pupillary responses of Cry 1 and Cry 2 knockout, $r d / r d$ mice were almost abolished in comparison to $r d / r d$ mice, suggesting that CRY may function as retinal photopigments. However, the same authors later showed that mutations in other essential circadian clock genes, mPeriod and Bmall also induced a significant lower pupillary light sensitivity, which demonstrated that the effect of CRY loss on nonvisual photoreception was due to a nonspecific loss of the circadian clock [7]. These results thus do not argue in favour of a direct photoreceptive role of CRY in mammals, at least not with respect to the pupillary response and a central clock phase shift (review in Felder-Schmittbuhl et al. [9]).

In mammals, the clock function of CRY is therefore assumed to be independent of light, even in the retina [24]. Indeed, so far in vertebrates, only one light-dependent function is assumed for retinal CRY, specifically the magnetic compass sense in birds (review in [35]). The assumed mechanism relies on radical pairs formed upon photoexcitation of CRY, the spin state of which is influenced by weak magnetic fields (MF). The spin states of these chemical intermediates, in turn, influence the rate of CRY activation, which is transduced into neuronal impulses through an as yet unknown pathway. Even though sensitivity to weak MF could hitherto only be demonstrated in the plant Arabidopsis thaliana [36] and fruit fly (Drosophila melanogaster) CRY [37], a wealth of evidence supports the involvement of CRY in the ability of birds to orient to the geomagnetic field [35]. From recent data, the magnetic sense in birds is based on a type IV CRY (CRY 4) localized in cones of the avian retina [38]. Mammals do not possess an ortholog of CRY4, and although a magnetic compass sense has also been attested in them [39], no solid indication exists to date that supports the involvement of CRY [40]. Of note, the CRY-based compass sense relies on the anisotropic part of the response of CRY to the $\mathrm{MF}$, i.e. the one that depends on the relative orientation of the MF. That anisotropic response, however, only represents a minor part of the total MF response of CRY, which indeed is mainly isotropic [35].

\section{Light responsiveness of mammalian CRY 2}

Even though no light dependence is assumed for the function of mammalian type II CRYs, some data suggest that CRY 2 of mammals is light responsive. Such responsiveness does not per se imply light dependence of a CRY function, but it does support the possibility of it.

\section{Binding of the FAD cofactor to CRY 2}

A prerequisite for CRY to fulfill a light-dependent function is that it binds the flavin cofactor FAD. Although that question remains debated [41, 42], the studies reviewed hereunder seem to rule out light-dependent functions in CRY 1, but support that possibility in CRY 2.

In mice, the ability of CRY 1 to form the heterodimer CRY1/PER2 that represses the CLOCK/BMAL1-dependent transcription has been shown not to depend on FAD, in contrast to that of Drosophila CRY [25]. In line with that in vitro observation, the FAD binding pocket of vertebrate CRY 1 is unoccupied when it is either in its ground state or in its active, heterodimeric, form $[32,43]$.

Contrary to CRY 1 , the crystal structure of mammalian CRY 2 supports the view that the FAD binding pocket has an effective, dynamic, affinity for FAD [44], suggesting that the FAD cofactor plays a role in its function. While noting that this affinity is only modest for the ground, oxidized, state of FAD, the authors point out that it depends on the redox state of FAD, and could thus be higher for FAD in its active, reduced, form [44]. Indeed, Hirano et al. [45] reported that FAD binds to human CRY 2 ( $h s$ CRY 2 ) and that this is affected by a single point mutation located in the phosphate loop of the FAD-binding domain that is responsible for a heritable sleep phenotype (familial advanced sleep phase). By subsequently studying that mutation in transgenic mice, 
they showed that it caused a reduction of the response (phase shift) of the circadian biorhythms to a light pulse [45].

\section{Light response of human CRY 2 in Drosophila}

Light responses of $h s \mathrm{CRY}$ have been reported in three different studies using transgenic Drosophila. First, photoreduction of $h s$ CRY 1 and 2 has been documented in Drosophila cells using fluorescence and electron paramagnetic resonance spectroscopic techniques [46]. Additionally, two studies have reported that $h s \mathrm{CRY}$ restore CRY-dependent behavioral responses to weak MF. As discussed above from the radical pair mechanism, such responses are presumed to rely on the light responsiveness of the CRY molecules [35]. Foley et al. [47] showed that hsCRY 2 rescues lightdependent magnetoreception in CRY-deficient flies. Furthermore, Fedele et al. [48] reported blue light $(450 \mathrm{~nm} \pm 20 \mathrm{~nm})$ dependent disruption of biorhythms in flies exposed to static or extremely low-frequency MF in the microtesla range, but only in flies expressing either native Drosophila CRY or $h s$ CRY 2 and not $h s$ CRY 1 (in the absence of Drosophila $\mathrm{CRY}$ ). These two last observations illustrate the difficulties of extrapolating from in vitro to in vivo, which might explain the discrepancies between the reported FAD binding to type II CRY in living cells [46], that was absent in purified CRY molecules [42].

\section{Discussion}

The identity of the photoreceptor(s) responsible for the synchronization of biorhythms of the mammalian retina with the light/dark cycle remains debated. The light entrainment appears to be effective from the UVA spectrum $(\geq 370 \mathrm{~nm})$ up to over $500 \mathrm{~nm}[8,11,12]$. According to the phase-shifting effect of light pulses observed both by Buhr et al. [11] and Calligaro et al. [12], the intensity threshold for that entrainment (respectively, at $417 \mathrm{~nm}$ and $465 \mathrm{~nm}$ ) lies between $10^{13}$ and $10^{14}$ photons $/ \mathrm{cm}^{2} / \mathrm{s}[11,12]$. Notwithstanding differences in the respective methodologies used (light entrainment vs pulse-induced phase shifting), two main contradictions emerge between the findings of these two research teams. Firstly, while Calligaro et al. [12] reported a role for rods, Buhr et al. [8] excluded it. Secondly, while Calligaro et al. [12] reported a response (phase shifting) to $520 \mathrm{~nm}$ light, Buhr et al. [11] did not observe any response (light entrainment) at $530 \mathrm{~nm}$. Calligaro et al. [12] considered this last discrepancy as "puzzling", i.e. as having no satisfactory explanation, even though it resulted from different experimental paradigms (pulse-induced phase-shifting vs light entrainment).

The dependence on rods reported by Calligaro et al. [12] was shown for a single dephasing light pulse between $15 \mathrm{~min}$ and $3 \mathrm{~h}$ of duration at an intensity 1 log lower than the one used by Buhr et al. [8] for the whole $12 \mathrm{~h}$ light phase of the light/dark cycle that they reported to light entrain retinal biorhythms in rodless mice. These results can be compared with the intensity- and duration-thresholds of the different activation pathways of ipRGCs for the light entrainment of central biorhythms. Indeed, while the "extrinsic" activation of ipRGCs by rods and cones is already effective as from intensities of $10^{9}$ to $10^{11}$ photons $/ \mathrm{cm}^{2} / \mathrm{s}$, as attested by roddependent phase shift [22], their "intrinsic", OPN4-dependent (rod-independent), activation is only effective above $10^{12}$ photons $/ \mathrm{cm}^{2} / \mathrm{s}$ at $480 \mathrm{~nm}$, with saturation at about $3 \times 10^{13}$ photons $/ \mathrm{cm}^{2} / \mathrm{s}[49,50]$. It is noteworthy here that OPN4dependent activation is characterized by a long response latency, and the ability of photon energy integration over time [51]. The observations by Calligaro et al. [12] and Buhr et al. [8] might thus be reconciled, for example, by supposing that the light entrainment of the retinal biorhythms is achieved by (a) specific photoreceptor cell(s) that require(s) extrinsic activation by rods below a certain light intensity and a certain duration of illumination, but that can work independently of extrinsic activation above that intensity and/or duration, as in the case of ipRGCs-dependent photoresponse [52].

As mentioned by Calligaro et al. [12], a role for rods would imply some process downstream of the photoreception by OPN2 in order to reconcile the intensities required for the light entrainment of retinal biorhythms with the much lower sensitivity threshold of that photopigment. In this respect, however, a recent observation has been made of an OPN2-dependent effect (dopamine release in the retina) that shows a bimodal behavior, with an inhibitory effect at a low light intensity and a stimulating effect at intensities above about $3 \times 10^{14}$ photons $/ \mathrm{cm}^{2} / \mathrm{s}$ [53]. Other questions about a role for OPN2 arise, notably, from the absence of response reported by Buhr et al. [11] to $530 \mathrm{~nm}$ light, and the report by the same authors of retinal light entrainment in rodless mice [8]. As mentioned above, a role for OPN5 in responses at $465 \mathrm{~nm}$ and above is incompatible with its wavelength sensitivity both in rodents and humans [18]. Furthermore, as noted by Calligaro et al. [12], recent studies failed to detect OPN5 expression in the retina of human and non-human primates $[18,21]$. Finally, as suggested by Calligaro et al. [12], a role for OPN1SW and thus of SW cones should again imply the involvement of some downstream process, such as in the above-discussed role of rods depending on intensity. However, such a role for OPN1SW was excluded by Buhr et al. $[8,11]$ who also excluded a role for OPN4, of which the sensitivity is moreover nearly null at $395 \mathrm{~nm}$. Finally, OPN3 has been ruled out by Buhr et al. [11]. Could the photoreceptor mediating the response be of non-opsin nature?

Here, we have reviewed data and arguments of different nature in support of the light responsiveness of mammalian 
CRY 2 and suggest a role for it in the light entrainment of retinal biorhythms (Fig. 4). Although it has already been evoked by Buhr et al. [8], this hypothesis has not yet been developed or studied. The hypothesis is confronted with many unknowns that need to be addressed because most of the supporting arguments are indirect. On the one hand, it is unknown whether actual binding of FAD to CRY per se implies that it fulfills a light-dependent function. For example, from a study on both CRY 1 and CRY 2, Hirano et al. [41] concluded that FAD stabilizes CRY and influences their clock function, simply because FAD competes with the ubiquitin ligase FBXL3 that labels CRY for degradation. On the other hand, as noted by Fedele et al. [48] and in line with the adaptability to cell environment that has been observed for the function of Drosophila CRY [54], the observations of a light response of $h s \mathrm{CRY}$ in transgenic Drosophila [47, 48], raises the possibility that the particular molecular environment of Drosophila cells has provided the biochemical environment or molecular interactors that allow mammalian CRY to respond to light. Alternatively, the difference between in vitro and in vivo could be critical, i.e. that FAD can bind to CRY 2 only in vivo. Finally, light responsiveness of CRY 2 might not automatically imply that its function in the retina does depend on light. Noteworthy here, although Hoang et al. [46] did report a light response for both $h s \mathrm{CRY}$ 1 and 2 in transgenic Drosophila, Fedele et al. [48] reported that only $h s \mathrm{CRY} 2$, thus not $h s \mathrm{CRY} 1$, could restore the (light-dependent) clock function of CRY in them.

Two characteristics of the light response reported for retinal biorhythms support the hypothesis of the involvement of CRY in their light entrainment. These are the large wavelength sensitivity range of these biorhythms and the relatively high light intensities that are required for their entrainment. First, the wavelength sensitivity of the oxidized form (ground state) of CRY covers the whole wavelength sensitivity range that has been commonly reported by Buhr et al. $[8,11]$ and Calligaro et al. [12] (Fig. 2). Second, the intensity threshold reported for the activation of CRY at $450 \mathrm{~nm}[27,28]$ is close to that reported by both Buhr et al. [11] and Calligaro et al. [12] for light-induced phase shift at $417 \mathrm{~nm}$ and $465 \mathrm{~nm}$, respectively. If CRY2 plays a role in the light entrainment of retinal biorhythms, different downstream mechanisms could transduce the photoactivation of CRY 2, such as an increased binding affinity to PER and/or CLOCK/BMAL1 (compared to CRY 1 that affinity is low for CRY 2 in its oxidized form [55]) or a light-induced interaction with another molecular partner, like in Drosophila [24]. Comparing the circadian light responses of the mammalian retina [8,11-13] with the CRY-based circadian light responses in Drosophila, one makes two interesting observations. First, in Drosophila, like in mice, a light pulse can cause a phase shift as from 15 min of duration [56]. Second, the phase shift caused by blue light in Drosophila shows an inverse relationship between the intensity and the duration of the light pulse required for that shift. Vinayak et al. [57] indeed reported that, as in plants [28], CRY-dependent signaling in Drosophila could integrate light intensity over time, with phase shifting requiring about $10^{16}$ photons $/ \mathrm{cm}^{2} / \mathrm{s}$ for a $10 \mathrm{~min}$ pulse of blue light and only about $10^{14}$ photons $/ \mathrm{cm}^{2} / \mathrm{s}$ for a $120 \mathrm{~min}$ pulse. This resembles the abovementioned phenomenon of light energy integration that is known for the OPN4-dependent light entrainment of central biorhythms
Fig. 4 Model of the hypothesis of the involvement of CRY 2 in the light-entrainment of the retinal biorhythms, in association with inputs from rods and, possibly, short-wavelength cones (SW). In retinal cells that express CRY 2, the biorhythms are directly synchronized with the light/dark phase due to the action of light on the activational state of CRY 2. In retinal cells, at the contrary to cells of other organs, only the photoactivated state of CRY 2 can play a role in the clock feedback loop. PER: period; CLOCK, BMAL1: transcription factors (only a part of the molecular clock machinery is shown) $[9,12,24,29]$

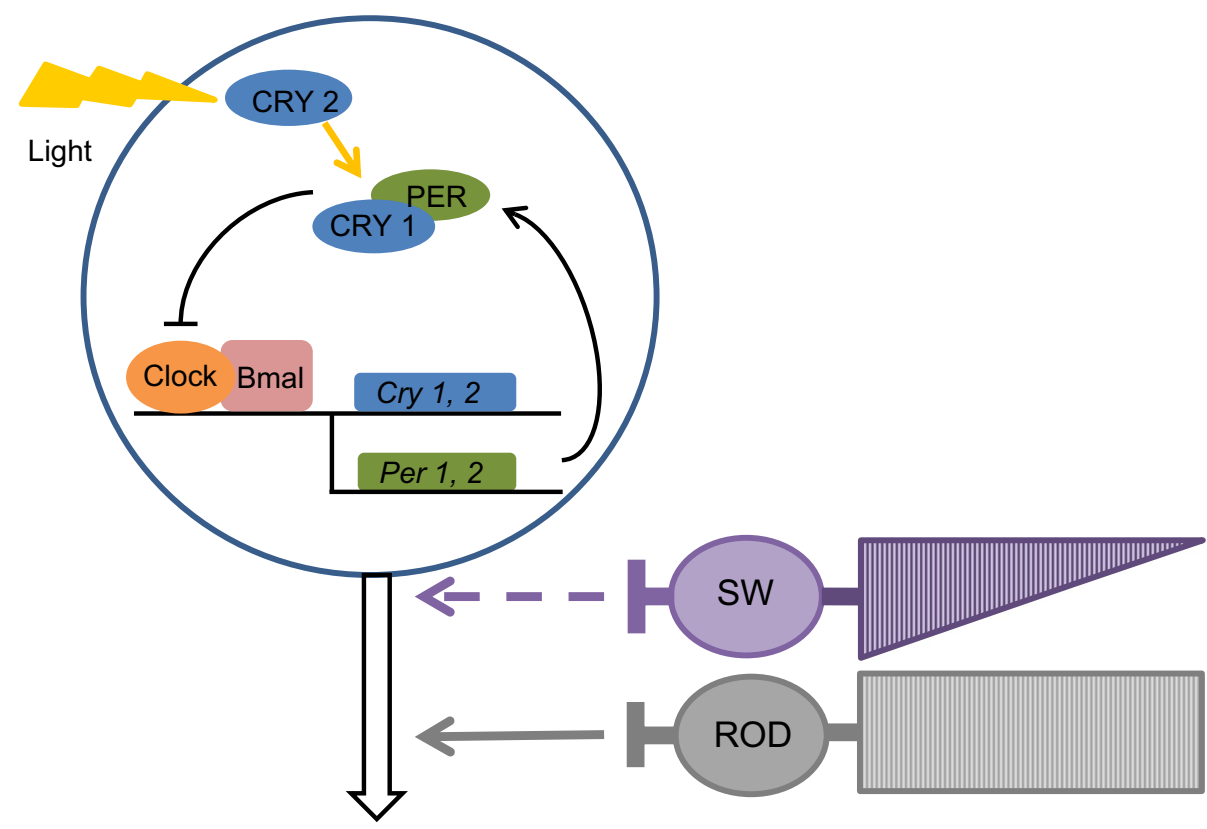

RETINAL BIORHYTHMS 
[51], and that Calligaro et al. [12] also noted, yet to a lesser extent, for the retinal biorhythms.

Further illustrating the fact that the debate about a lightdependent role of CRY in mammalian retina is ongoing, Michael et al. [58] recently summarized different arguments in support of such a role. For example, transgenic mice that lacked both CRY and opsins (absence of photoreceptor cells, or vitamin A depletion) had substantially less circadian light responses compared to those lacking either only CRY, or only opsins [59-61].

\section{Research avenues}

How can the hypothesis be tested? A critical investigation of the role of CRY 2 in the light entrainment of retinal biorhythms would in principle require the use of CRY 2 knockout animals (ideally of a diurnal species). A full knockout will, however, disturb the intrinsic biorhythms themselves (CRY 2 knockout mice have a circadian phenotype [7, 30]). As the present hypothesis specifically addresses the light response of CRY 2, which itself relies on the FAD cofactor, one possible solution could be to use a mutant form of CRY 2 that is unable to bind FAD, such as the mutant form A260T that Hirano et al. [45] tested in mice. Another way to test the involvement of CRY could be to study retinal explants of diurnal mammals, which likely lack OPN5, under 360-370 nm light and at intensities above the intensity threshold of CRY, that is above about $10^{14}$ photons/ $\mathrm{cm}^{2} / \mathrm{s}$. Indeed, any response (phase shift) at such wavelength would suggest the involvement of CRY (cf. Fig. 2). For these experiments, it would be crucial that the expression pattern of both CRY 2 and OPN5 in the retina of diurnal mammals will be established using well-characterized specific antibodies. Additionally, the controversy about the role of rods $[8,12]$ might be further explored by studying the phase shift of biorhythms of retinal explants from rodless mice by testing a large range of pulse durations and light intensities, for example, between $10^{13}$ and $10^{16}$ photons $/ \mathrm{cm}^{2} / \mathrm{s}$. Indeed, this might uncover the possibility of a cutoff intensity and/ or duration, below which rods are required and above which they are dispensable.

\section{Conclusion}

At the current state of knowledge, mammalian CRY 2 might have kept the ability to respond to light. We reviewed several observations that led us to suggest their involvement in the light entrainment of retinal biorhythms, plausibly in collaboration with rods [12], as recently suggested by Buhr et al. [8] and in line with the light dependence that had been formerly proposed for the function of CRY in the mammalian retina [33]. If future experiments support our hypothesis, they would help to answer the still pending question of CRY 2 function in the mammalian retina and might have consequences for studies on magnetic sensitivity in mammals $[47,48,62]$.

Acknowledgements We are indebted to Martha Daniel for proof reading the manuscript and thankful to three anonymous referees for helpful comments that improved the quality of the manuscript.

Author contributions JV developed the hypothesis. All authors wrote the manuscript.

\section{Compliance with ethical standards}

Conflict of interest The authors declare there is no conflict of interest regarding the publication of this article.

\section{References}

1. Astiz M, Heyde I, Oster H (2019) Mechanisms of communication in the mammalian circadian timing system. Int J Mol Sci 20:E343. https://doi.org/10.3390/ijms20020343

2. Husse J, Eichele G, Oster H (2015) Synchronization of the mammalian circadian timing system: light can control peripheral clocks independently of the SCN clock: alternate routes of entrainment optimize the alignment of the body's circadian clock network with external time. BioEssays 37:1119-1128. https://doi.org/10.1002/ bies. 201500026

3. Welz PS, Zinna VM, Symeonidi A, Koronowski KB, Kinouchi K, Smith JG, Guillén IM, Castellanos A, Furrow S, Aragón F, Crainiciuc G, Prats N, Caballero JM, Hidalgo A, Sassone-Corsi P, Benitah SA (2019) BMAL1-driven tissue clocks respond independently to light to maintain homeostasis. Cell 177:1436-1447. https://doi.org/10.1016/j.cell.2019.05.009

4. Fan SM, Chang YT, Chen CL, Wang WH, Pan MK, Chen WP, Huang WY, Xu Z, Huang HE, Chen T, Plikus MV, Chen SK, Lin SJ (2018) External light activates hair follicle stem cells through eyes via an ipRGC-SCN-sympathetic neural pathway. Proc Natl Acad Sci USA 115:E6880-E6889. https://doi.org/10.1073/ pnas. 1719548115

5. Buhr ED, Vemaraju S, Diaz N, Lang RA, Van Gelder RN (2019) Neuropsin (OPN5) mediates local light-dependent induction of circadian clock genes and circadian photoentrainment in exposed murine skin. Curr Biol 29:1-10. https://doi.org/10.1016/j. cub.2019.08.063

6. Tosini G, Menaker M (1996) Circadian rhythms in cultured mammal retina. Science 272:419-421. https://doi.org/10.1126/scien ce. 272.5260 .419

7. Owens L, Buhr ED, Tu DC, Lamprecht TL, Lee J, Van Gelder RN (2012) Effect of circadian clock gene mutations on nonvisual photoreception in the mouse. Investig Ophthalmol Vis Sci 53:454-460. https://doi.org/10.1167/iovs.11-8717

8. Buhr ED, Van Gelder RN (2014) Local photic entrainment of the retinal circadian oscillator in the absence of rods, cones, and melanopsin. Proc Natl Acad Sci USA 111:8625-8630. https://doi. org/10.1073/pnas.1323350111

9. Felder-Schmittbuhl MP, Buhr ED, Dkhissi-Benyahya O, Hicks D, Peirson SN, Ribelayga CP, Sandu C, Spessert R, Tosini G (2018) Ocular clocks: adapting mechanisms for eye functions and health. Investig Ophthalmol Vis Sci 59:4856-4870. https://doi. org/10.1167/iovs.18-24957 
10. Tosini G, Menaker M (1998) The clock in the mouse retina: melatonin synthesis and photoreceptor degeneration. Brain Res 789:221-228. https://doi.org/10.1016/s0006-8993(97)01446-7

11. Buhr ED, Yue WW, Ren X, Jiang Z, Liao HW, Mei X, Vemaraju S, Nguyen MT, Reed RR, Lang RA, Yau KW, Van Gelder RN (2015) Neuropsin (OPN5)-mediated photoentrainment of local circadian oscillators in mammalian retina and cornea. Proc Natl Acad Sci USA 112:13093-13098. https://doi.org/10.1073/ pnas. 1516259112

12. Calligaro H, Coutanson C, Najjar RP, Mazzaro N, Cooper HM, Haddjeri N, Felder-Schmittbuhl MP, Dkhissi-Benyahya O (2019) Rods contribute to the light-induced phase shift of the retinal clock in mammals. PLoS Biol 17:e2006211. https://doi. org/10.1371/journal.pbio.2006211

13. Ruan GX, Allen GC, Yamazaki S, McMahon DG (2008) An autonomous circadian clock in the inner mouse retina regulated by dopamine and GABA. PLoS Biol 6:e249. https://doi.org/10.1371/ journal.pbio.0060249

14. Peirson SN, Brown LA, Pothecary CA, Benson LA, Fisk AS (2018) Light and the laboratory mouse. J Neurosci Methods 15(300):26-36. https://doi.org/10.1016/j.jneumeth.2017.04.007

15. Brown TM (2016) Using light to tell the time of day: sensory coding in the mammalian circadian visual network. J Exp Biol 219(Pt 12):1779-1792. https://doi.org/10.1242/jeb.132167

16. Haltaufderhyde K, Ozdeslik RN, Wicks NL, Najera JA, Oancea E (2015) Opsin expression in human epidermal skin. Photochem Photobiol 91:117-123. https://doi.org/10.1111/php.12354

17. Spitschan M (2019) Melanopsin contribution to non-visual and visual function. Curr Opin Behav Sci 30:67-72. https://doi. org/10.1016/j.cobeha.2019.06.004

18. Kojima D, Mori S, Torii M, Wada A, Morishita R, Fukada Y (2011) UV-sensitive photoreceptor protein OPN5 in humans and mice. PLoS One 6:e26388. https://doi.org/10.1371/journ al.pone. 0026388

19. Liu H, Zhong D, Lin C (2010) Searching for a photocycle of the cryptochrome photoreceptors. Curr Opin Plant Biol 13:578-586. https://doi.org/10.1016/j.pbi.2010.09.005

20. Hut RA, Scheper A, Daan S (2000) Can the circadian system of a diurnal and a nocturnal rodent entrain to ultraviolet light ? J Comp Physiol A 186:707-715

21. Mure LS, Le HD, Benegiamo G, Chang MW, Rios L, Jillani N, Ngotho M, Kariuki T, Dkhissi-Benyahya O, Cooper HM, Panda S (2018) Diurnal transcriptome atlas of a primate across major neural and peripheral tissues. Science 359:eaao0318. https://doi. org/10.1126/science.aao0318

22. Lall GS, Revell VL, Momiji H, Al Enezi J, Altimus CM, Güler AD, Aguilar C, Cameron MA, Allender S, Hankins MW, Lucas RJ (2010) Distinct contributions of rod, cone, and melanopsin photoreceptors to encoding irradiance. Neuron 66:417-428. https ://doi.org/10.1016/j.neuron.2010.04.037

23. Oztürk N, Song SH, Ozgür S, Selby CP, Morrison L, Partch C, Zhong D, Sancar A (2007) Structure and function of animal cryptochromes. Cold Spring Harb Symp Quant Biol 72:119-131. https ://doi.org/10.1101/sqb.2007.72.015

24. Chaves I, Pokorny R, Byrdin M, Hoang N, Ritz T, Brettel K, Essen LO, van der Horst GT, Batschauer A, Ahmad M (2011) The cryptochromes: blue light photoreceptors in plants and animals. Annu Rev Plant Biol 62:335-364. https://doi.org/10.1146/annur ev-arplant-042110-103759

25. Czarna A, Berndt A, Singh HR, Grudziecki A, Ladurner AG, Timinszky G, Kramer A, Wolf E (2013) Structures of Drosophila cryptochrome and mouse cryptochrome1 provide insight into circadian function. Cell 153:1394-1405. https://doi.org/10.1016/j. cell.2013.05.011

26. Zoltowski BD, Chelliah Y, Wickramaratne A, Jarocha L, Karki N, $\mathrm{Xu}$ W, Mouritsen H, Hore PJ, Hibbs RE, Green CB, Takahashi JS
(2019) Chemical and structural analysis of a photoactive vertebrate cryptochrome from pigeon. Proc Natl Acad Sci USA. https ://doi.org/10.1073/pnas.1907875116

27. Liu Q, Wang Q, Deng W, Wang X, Piao M, Cai D, Li Y, Barshop WD, Yu X, Zhou T, Liu B, Oka Y, Wohlschlegel J, Zuo Z, Lin C (2017) Molecular basis for blue light-dependent phosphorylation of Arabidopsis cryptochrome 2. Nat Commun 8:15234. https:// doi.org/10.1038/ncomms 15234

28. Weidler G, Zur Oven-Krockhaus S, Heunemann M, Orth C, Schleifenbaum F, Harter K, Hoecker U, Batschauer A (2012) Degradation of Arabidopsis CRY2 is regulated by SPA proteins and phytochrome A. Plant Cell 24:2610-2623. https://doi. org/10.1105/tpc. 112.098210

29. Gustafson CL, Partch CL (2015) Emerging models for the molecular basis of mammalian circadian timing. Biochemistry 54:134 149. https://doi.org/10.1021/bi500731f

30. Wong JCY, Smyllie NJ, Banks GT, Pothecary CA, Barnard AR, Maywood ES, Jagannath A, Hughes S, van der Horst GTJ, MacLaren RE, Hankins MW, Hastings MH, Nolan PM, Foster RG, Peirson SN (2018) Differential roles for cryptochromes in the mammalian retinal clock. FASEB J 32:4302-4314. https:// doi.org/10.1096/fj.201701165RR

31. Thompson CL, Bowes Rickman C, Shaw SJ, Kelly U, Sancar A, Rickman DW (2003) Expression of the blue-light receptor cryptochrome in the human retina. Investig Ophthalmol Vis Sci 44:4515-4521. https://doi.org/10.1167/iovs.03-0303

32. Wang X, Jing C, Selby CP, Chiou YY, Yang Y, Wu W, Sancar A, Wang J (2018) Comparative properties and functions of type 2 and type 4 pigeon cryptochromes. Cell Mol Life Sci 75:4629-4641. https://doi.org/10.1007/s00018-018-2920-y

33. Partch CL, Sancar A (2005) Cryptochromes and circadian photoreception in animals. Methods Enzymol 393:726-745. https:// doi.org/10.1016/S0076-6879(05)93038-3

34. Van Gelder RN, Wee R, Lee JA, Tu DC (2003) Reduced pupillary light responses in mice lacking cryptochromes. Science 299:222. https://doi.org/10.1126/science.1079536

35. Hore PJ, Mouritsen H (2016) The radical-pair mechanism of magnetoreception. Annu Rev Biophys 45:299-344. https://doi. org/10.1146/annurev-biophys-032116-094545

36. Kattnig DR, Evans EW, Déjean V, Dodson CA, Wallace MI, Mackenzie SR, Timmel CR, Hore PJ (2016) Chemical amplification of magnetic field effects relevant to avian magnetoreception. Nat Chem 8:384-391. https://doi.org/10.1038/nchem.2447

37. Sheppard DM, Li J, Henbest KB, Neil SR, Maeda K, Storey J, Schleicher E, Biskup T, Rodriguez R, Weber S, Hore PJ, Timmel CR, Mackenzie SR (2017) Millitesla magnetic field effects on the photocycle of an animal cryptochrome. Sci Rep 7:42228. https:// doi.org/10.1038/srep42228

38. Günther A, Einwich A, Sjulstock E, Feederlee R, Bolte P, Koch KW, Solov'yov IA, Mouritsen H (2018) Double-cone localization and seasonal expression pattern suggest a role in magnetoreception for European robin cryptochrome 4. Curr Biol 28:211-223. https://doi.org/10.1016/j.cub.2017.12.003

39. Begall S, Malkemper EP, Ceverny J, Nemec P, Burda H (2013) Magnetic alignment in mammals and other animals. Mammal Biol 78:10-20. https://doi.org/10.1016/j.mambio.2012.05.005

40. Begall S, Burda H, Malkemper EP (2014) Magnetoreception in mammals. In: Naguib M (ed) Advances in the study of behavior, vol 46. Elsevier, Amsterdam, pp 45-88. https://doi.org/10.1016/ B978-0-12-800286-5.00002-X

41. Hirano A, Braas D, Fu YH, Ptáček LJ (2017) FAD regulates cryptochrome protein stability and circadian clock in mice. Cell Rep 19:255-266. https://doi.org/10.1016/j.celrep.2017.03.041

42. Kutta RJ, Archipowa N, Johannissen LO, Jones AR, Scrutton NS (2017) Vertebrate cryptochromes are vestigial flavoproteins. Sci Rep 7:44906. https://doi.org/10.1038/srep44906 
43. Schmalen I, Reischl S, Wallach T, Klemz R, Grudziecki A, Prabu JR, Benda C, Kramer A, Wolf E (2014) Interaction of circadian clock proteins CRY1 and PER2 is modulated by zinc binding and disulfide bond formation. Cell 157:1203-1215. https://doi. org/10.1016/j.cell.2014.03.057

44. Xing W, Busino L, Hinds TR, Marionni ST, Saifee NH, Bush MF, Pagano M, Zheng N (2013) SCF(FBXL3) ubiquitin ligase targets cryptochromes at their cofactor pocket. Nature 496:64-68. https ://doi.org/10.1038/nature11964

45. Hirano A, Shi G, Jones CR, Lipzen A, Pennacchio LA, Xu Y, Hallows WC, McMahon T, Yamazaki M, Ptáček LJ, Fu YH (2016) A cryptochrome 2 mutation yields advanced sleep phase in humans. Elife 5:e16695. https://doi.org/10.7554/eLife.16695

46. Hoang N, Schleicher E, Kacprzak S, Bouly JP, Picot M, Wu W, Berndt A, Wolf E, Bittl R, Ahmad M (2008) Human and Drosophila cryptochromes are light activated by flavin photoreduction in living cells. PLoS Biol 6:e160. https://doi.org/10.1371/journ al.pbio.0060160

47. Foley LE, Gegear RJ, Reppert SM (2011) Human cryptochrome exhibits light-dependent magnetosensitivity. Nat Commun 2:356. https://doi.org/10.1038/ncomms1364

48. Fedele G, Edwards MD, Bhutani S, Hares JM, Murbach M, Green EW, Dissel S, Hastings MH, Rosato E, Kyriacou CP (2014) Genetic analysis of circadian responses to low frequency electromagnetic fields in Drosophila melanogaster. PLoS Genet 10:e1004804. https://doi.org/10.1371/journal.pgen.1004804

49. Reifler AN, Chervenak AP, Dolikian ME, Benenati BA, Meyers BS, Demertzis ZD, Lynch AM, Li BY, Wachter RD, Abufarha FS, Dulka EA, Pack W, Zhao X, Wong KY (2015) The rat retina has five types of ganglion-cell photoreceptors. Exp Eye Res 130:1728. https://doi.org/10.1016/j.exer.2014.11.010

50. Zhao X, Stafford BK, Godin AL, King WM, Wong KY (2014) Photoresponse diversity among the five types of intrinsically photosensitive retinal ganglion cells. J Physiol 592:1619-1636. https ://doi.org/10.1113/jphysiol.2013.262782

51. Mure LS, Hatori M, Zhu Q, Demas J, Kim IM, Nayak SK, Panda $S$ (2016) Melanopsin-encoded response properties of intrinsically photosensitive retinal ganglion cells. Neuron 90:1016-1027. https ://doi.org/10.1016/j.neuron.2016.04.016

52. Lucas RJ, Lall GS, Allen AE, Brown TM (2012) How rod, cone, and melanopsin photoreceptors come together to enlighten the mammalian circadian clock. Prog Brain Res 199:1-18. https:// doi.org/10.1016/B978-0-444-59427-3.00001-0

53. Pérez-Fernández V, Milosavljevic N, Allen AE, Vessey KA, Jobling AI, Fletcher EL, Breen PP, Morley JW, Cameron MA (2019) Rod photoreceptor activation alone defines the release of dopamine in the retina. Curr Biol 29(763-774):e5. https://doi. org/10.1016/j.cub.2019.01.042

54. Collins B, Mazzoni EO, Stanewsky R, Blau J (2006) Drosophila cryptochrome is a circadian transcriptional repressor. Curr Biol 16:441-449. https://doi.org/10.1016/j.cub.2006.01.034

55. Rosensweig C, Reynolds KA, Gao P, Laothamatas I, Shan Y, Ranganathan R, Takahashi JS, Green CB (2018) An evolutionary hotspot defines functional differences between cryptochromes. Nat Commun 9:1138. https://doi.org/10.1038/s41467-018-03503-6

56. Kaladchibachi S, Negelspach DC, Fernandez F (2018) Circadian phase-shifting by light: beyond photons. Neurobiol Sleep Circadian Rhythms 5:8-14. https://doi.org/10.1016/j.nbscr.2018.03.003

57. Vinayak P, Coupar J, Hughes SE, Fozdar P, Kilby J, Garren E, Yoshii T, Hirsh J (2013) Exquisite light sensitivity of Drosophila melanogaster cryptochrome. PLoS Genet 9:e1003615. https://doi. org/10.1371/journal.pgen.100361

58. Michael AK, Fribourgh JL, Van Gelder RN, Partch CL (2017) Animal cryptochromes: divergent roles in light perception, circadian timekeeping and beyond. Photochem Photobiol 93:128-140. https://doi.org/10.1111/php.12677

59. Selby CP, Thompson C, Schmitz TM, Van Gelder RN, Sancar A (2000) Functional redundancy of cryptochromes and classical photoreceptors for nonvisual ocular photoreception in mice. Proc Natl Acad Sci USA 97:14697-14702. https://doi.org/10.1073/ pnas. 260498597

60. Thompson CL, Blaner WS, Van Gelder RN, Lai K, Quadro L, Colantuoni V, Gottesman ME, Sancar A (2001) Preservation of light signaling to the suprachiasmatic nucleus in vitamin A-deficient mice. Proc Natl Acad Sci USA 98:11708-11713. https://doi. org/10.1073/pnas.201301498

61. Thompson CL, Selby CP, Van Gelder RN, Blaner WS, Lee J, Quadro L, Lai K, Gottesman ME, Sancar A (2004) Effect of vitamin A depletion on nonvisual phototransduction pathways in cryptochromeless mice. J Biol Rhythms 19:504-517. https://doi. org/10.1177/0748730404270519

62. Vanderstraeten J, Gailly P, Malkemper EP (2018) Low-light dependence of the magnetic field effect on cryptochromes: possible relevance to plant ecology. Front Plant Sci 9:121. https://doi. org/10.3389/fpls.2018.00121

Publisher's Note Springer Nature remains neutral with regard to jurisdictional claims in published maps and institutional affiliations. 